\title{
METODOLOGIAS CRIATIVAS NO PROCESSO DE ENSINO E DE APRENDIZAGEM NA EDUCAÇÃO BÁSICA
}

\author{
Bettina Steren dos Santos \\ Carla Spagnolo \\ Caroline Bücker
}

\begin{abstract}
Resumo
Durante muito tempo, a intenção da educação escolar esteve fortemente vinculada com a reprodução de modelos de mundo existentes. Com o surgimento das tecnologias da informação e comunicação, as mudanças culturais e sociais ficaram mais evidentes, exigindo das instituições de ensino mais mobilização para repensar sua postura diante das necessidades contemporâneas. O objetivo desse artigo é compreender a aplicabilidade das metodologias criativas através do Design Thinking, nos processos de ensino e aprendizagem na educação escolar básica. O estudo, de abordagem qualitativa, com suporte da técnica de observação participativa, baseia-se em relatos de uma experiência de que envolveu estudantes, professores, pais e gestores de uma escola privada do Rio Grande do Sul-Brasil em seis oficinas de Design Thinking. Os resultados apontam para o desenvolvimento da colaboração e criatividade entre os participantes e o planejamento de novas ações para qualificar os processos de ensino e aprendizagem e as relações entre as pessoas que fazem parte do ambiente escolar.
\end{abstract}

Palavras-chave: aprendizagem; metodologias criativas; colaboração.

\section{CREATIVE METHODOLOGIES IN THE TEACHING AND LEARNING PROCESS IN BASIC EDUCATION}

\begin{abstract}
For a long time, the intention of school education has been strongly linked with the reproduction of existing world models. With the advent of information and communication technologies, cultural and social changes were more evident, requiring from educational institutions more mobilization to rethink its position before the con-temporary needs. The aim was to understand the applicability of creative methodologies through Design Thinking in teaching and learning in primary school education. The study adopted a qualitative approach, based on reports of an experiment involving students, teachers, parents and administrators during six workshops of Design Thinking in a private school in Rio Grande do Sul, Brazil. The results point to the development of collaboration and creativity among the participants and the planning of new shares to qualify the process of teaching and learning and the relationship between people who are part of the school environment.
\end{abstract}

Keywords: learning; creative methodologies; collaboration.

\section{METODOLOGÍAS CREATIVAS EN EL PROCESO DE ENSEÑANZA Y APRENDIZAJE EN EDUCACIÓN BÁSICA}

Resumen

Durante mucho tiempo, la intención de la educación escolar estuvo fuertemente vinculada a la reproducción de modelos mundiales existentes. Con el surgimiento de las tecnologías de la información y la comunicación, los cambios culturales y sociales se hicieron más evidentes, lo que obligó a las instituciones educativas a movilizarse más para repensar su postura frente a las necesidades contemporáneas. El propósito de este artículo es comprender la efectividad de las metodologías creativas a través del Design Thinking, en los procesos de enseñanza y aprendizaje en la educación escolar básica. El estudio, con un enfoque cualitativo, se basa en informes de una experiencia que involucró a estudiantes, maestros, padres y gerentes de una 
escuela privada en Rio Grande do Sul-Brasil en seis talleres de Design Thinking. Los resultados apuntan al desarrollo de la colaboración y la creatividad entre los participantes y la planificación de nuevas acciones para calificar los procesos de enseñanza y aprendizaje y las relaciones entre las personas que forman parte del entorno escolar.

Palabras clave: aprendizaje; metodologías creativas; colaboración.

\section{INTRODUÇÃO}

O mundo está mudando de maneira acelerada e essas transformações são evidenciadas com mais rapidez fora da escola do que nas estruturas que concernem os ambientes escolares, sejam elas de recursos físicos, pessoais, curriculares, entre outros. Esse mundo cambiante em que hoje vivemos é totalmente diferente do mundo analógico que muitas pessoas vivenciaram há poucas décadas atrás. Essas mudanças devem atender as demandas contemporâneas com uma visão mais ampla e crítica da realidade.

As lembranças da educação escolar até a década de noventa, remetem-se ao ensino centrado nos professores, os quais eram detentores de todo o conhecimento, e a imobilidade na sala de aula fazia parte do processo de aprendizagem. As tecnologias utilizadas eram essencialmente o giz, quadro, caderno, papel, mimeografo, retroprojetor. Tais práticas atenderam os objetivos daquela época, pois era possível "vencer" os conteúdos programáticos planejados para determinada série, todavia, para quem não conseguisse aprender algum conteúdo, definitivamente, reprovava e permanecia na mesma série até que alcançasse os objetivos impostos pelas instituições.

Diante de tal cenário, questionamos até que ponto essa é uma realidade pertencente ao passado. Compactuamos com as afirmações de Martín-Barbero (2000), ao afirmar que, apesar de estarmos vivenciando mudanças evolutivas, o modelo predominante na escola ainda é vertical, autoritário na relação entre docentes e estudantes e linearmente sequencial no aprendizado. Isso quer dizer que o modelo de ensino permanece estático e, portanto, enquanto permanecer a verticalidade nas relações e a sequencialidade no modelo pedagógico, não teremos avanços nos resultados alcançados.

Necessitamos de uma visão mais complexa e sistêmica da Educação. Os fenômenos educativos são multidimensionais e dependem de atores, ideias, processos e estruturas. Em sua obra "Para que educamos hoy? ", Perez Lindo (2010) indaga sobre o real sentido da educação escolar e coloca-se em defesa das declarações da UNESCO, quando falam do sentido de educar com uma amplitude maior: educar para aprender a pensar, para aprender a conviver, para aprender a ser e para aprender a resolver problemas. Por isso, nessa mesma linha de pensamento, Pérez Gomes (2015) afirma que o ensino frontal, simultâneo e homogêneo é incompatível com esta nova estrutura da sociedade contemporânea, e exigirá das professoras e professores o desenvolvimento de uma metodologia mais flexível e plural, bem como, uma atenção mais personalizada aos estudantes.

Diante de tais inquietudes, emergem indagações que nos movem para novas pesquisas e para a busca de distintas alternativas de mobilização e inovação em práticas referentes à educação escolar: Como pensar práticas diferentes e inovadoras? Como envolver todas as pessoas que fazem parte do processo educativo no planejamento das práticas escolares? Como trabalhar de forma mais criativa e colaborativa no ambiente escolar? Como escutar a todos para aprender e desenvolver um projeto pedagógico que seja do interesse dos educadores e educandos?

O objetivo desse artigo é compreender a aplicabilidade das metodologias criativas, através do Design Thinking, nos processos de ensino e de aprendizagem na educação escolar básica. $\mathrm{O}$ estudo, de abordagem qualitativa, com suporte da técnica de observação participativa, baseia-se em relatos de uma experiência de estudantes, professores, pais e gestores de uma escola privada de Porto Alegre, Rio Grande do Sul. Os participantes tiveram a oportunidade de participar de seis 
oficinas organizadas através da metodologia Design Thinking. As oficinas aconteceram no período de três meses, sendo que os encontros aconteciam a cada quinze dias. $\mathrm{O}$ espaço, denominado Laboratório de Aprendizagem, contribuiu para a mobilidade e aproximação das pessoas, bem como para a utilização de diferentes tecnologias. Para dar suporte teórico a essa pesquisa, utilizamos diferentes autores, os quais contribuíram para fomentar a cientificidade e no desenvolvimento de construtos que auxiliaram na compreensão e ampliação conceitual.

\section{EDUCAÇÃO ESCOLAR: REALIDADE E PERSPECTIVAS NO PROCESSO DE ENSINO E DE APRENDIZAGEM}

A escola como instituição social alcança um novo desenvolvimento como consequência da Revolução Industrial, da mecanização do trabalho, da produção em massa e da concentração urbana da população durante o século XIX, consolidando-se no presente século com a generalização da escolaridade obrigatória e gratuita nas sociedades industriais. Tudo isso, produz sem dúvida, mudanças notáveis nas próprias demandas de aprendizagem geradas pelo contexto educativo. Por um lado, podemos olhar positivamente a inserção de todos os indivíduos no ambiente escolar, no entanto, por outro lado, parece haver uma produção linear de conhecimento, no intuito de formar pessoas que possam cumprir com seu "dever" de cidadão: ordem e progresso.

No passado, o objetivo da educação estava fortemente baseado em sedimentar e multiplicar modelos de mundo existentes (MOSQUERA, 2000) e fazer com que os alunos absorvessem e replicassem tais modelos. Segundo o autor, o surgimento da modernidade e da pós-modernidade gerou mudanças culturais e sociais que se refletiram na educação, entre outros âmbitos da sociedade. É exatamente por esse motivo que se deve refletir e repensar sobre os objetivos educacionais para os dias e para o mundo de hoje.

A preocupação com a qualidade do ensino nas escolas está presente em muitas discussões que envolvem a comunidade escolar e, em geral, grande parte da sociedade. Os meios de comunicação divulgam sobre os resultados e "rankings" classificando as melhores instituições. Diante desses resultados quantitativos, os pais, os professores e professoras, a equipe diretiva, e os próprios estudantes, comparam esses resultados entre diferentes instituições e com suas próprias vivências de aprendizagem em outros períodos. A avaliação em larga escala passa a ser determinante para a chamada qualidade da educação, pois, é a partir dessa lógica, que se define o currículo, a formação de professores e o trabalho docente. Para Damasceno (2012), cada vez mais os professores passam a ter tarefas bem definidas e delimitadas, tendo sempre como finalidade o alcance de indicadores de bom desempenho dos alunos e alunas. A escola, assim, mediante as exigências começa a se estruturar para atingir os objetivos estipulados por meio das "provas", invertendo, desse modo, a função da avaliação educacional e, principalmente, determinando o currículo escolar.

Portanto, se pretendemos ter um sistema educacional de qualidade, o primeiro passo "é quebrar as nozes para saber o que tem dentro", como nos convida a epígrafe desse texto de Machado de Assis. É necessário um amplo debate sobre o que se entende por esta qualidade e qual o currículo necessário a um projeto educativo que possibilite aos estudantes uma formação para além do domínio do português e da matemática. (DAMASCENO, 2012, p.163)

Tudo isso nos faz pensar que boa parte de nossa vida passamos na escola e destinamos a ela uma grande quantidade de recursos, sejam eles caracterizados como o tempo, materiais e o próprio envolvimento com todas as atividades que fazem parte do currículo. E o que fizemos, ou realizamos, com o tempo que estamos na escola? Sancho (2013), afirma que para muitos, a escola acaba exercendo mais influência do que o esperado, mas nem sempre no sentido desejado. $\mathrm{O}$ 
grande problema colocado pela autora é sobre o currículo baseado no modelo epistemológico empirista, o qual se manteve, ou mantém, por mais tempo estruturando as práticas escolares. Esse currículo priorizou a docilidade, a capacidade de suportar o sem sentido, respondendo apenas quando é solicitado, além do mais, não oportunizou todas as pessoas a aprenderem.

Nesse sentido, fala-se em porcentagens elevadas de analfabetos funcionais, visuais, entre outros. São pessoas que frequentaram a escola, aprenderam a ler e a escrever e obtiveram um diploma. Isso significa que oito, dez ou doze anos de educação escolar não preparam um importante número de indivíduos para aprender (SANCHO, 2013). Além disso, a ausência de incentivo à curiosidade e a criatividade impede a continuidade no desenvolvimento de outros saberes e a aplicabilidade de conhecimentos e habilidades no cotidiano das próprias vidas.

Em suma, o estágio escolar foi e continua sendo considerado como algo fechado em si mesmo: aprende-se na escola, para aprovar e satisfazer a família e os professores, ou para estar preparado para passar à etapa educativa seguinte. A ideia da escola como um lugar para reforçar os pilares da aprendizagem, a curiosidade, a constância, a crítica e o rigor está para se desenvolver de forma generalizada. [...]Daí a necessidade de se transformar a escola em um lugar onde se aprende para o momento e para continuar aprendendo ao longo da vida. (SANCHO, 2013, p. 31)

Com base nessas convicções, acreditamos que o ambiente escolar tem como premissa favorecer as condições de aprendizagem e criar situações em que o processo de ensinar e aprender sejam constantes e proveitosos para as pessoas. A escola é o lugar para aprender e ultrapassar os limites das próprias vivências, considerando-se a realidade e as necessidades vigentes dos estudantes que fazem parte desse ambiente.

O termo aprendizagem, em uma perspectiva sócio-histórica, é entendido como uma perspectiva mais ampla. Quando Vygotsky refere-se à aprendizagem, considera tanto o processo de ensino quanto o de aprendizagem em uma perspectiva de desenvolvimento qualitativo, que abrange as funções elementares e superiores. No caso das funções superiores, a aprendizagem acontece diante da apropriação e da internalização de instrumentos e signos em um contexto de interação. (VYGOTSKI, 1979).

Nessa mesma linha de pensamento, Pozo (2002) afirma que a nossa aprendizagem responde não só a um desenho genético, mas principalmente a um desenho cultural. Cada sociedade, cada cultura gera suas próprias formas de aprendizagem, sua cultura de aprendizagem.

Para Vygotsky (1979), é pela aprendizagem com os outros que o indivíduo constrói constantemente o conhecimento, promovendo o desenvolvimento mental e passando, desse modo, de um ser biológico a um ser humano. Enfatiza que o desenvolvimento e a aprendizagem estão relacionados desde o nascimento da criança, sendo que a aprendizagem resulta do desenvolvimento e este não ocorre sem a aprendizagem. Ambos ocorrem a partir de um movimento dialético. A aprendizagem somente acontece quando os instrumentos, os signos, os símbolos e as pautas do colega com o qual interage podem ser incorporados pela criança. A aprendizagem também depende do desenvolvimento potencial do sujeito, bem como da relação existente entre propostas teóricas e práticas pedagógicas.

Sabemos que falar de aprendizagem, implica em variáveis que interferem diretamente no processo de desenvolvimento das pessoas em aspectos biológicos, psicológicos, sociais e culturais, no entanto, apontamos os fatores culturais como uma das variáveis de valor considerável, na medida em que propõe modos de pensar e agir. É a cultura que pode induzir as aprendizagens através dos costumes, das práticas sociais, das ideologias predominantes. Pelo fato de que a cultura induz as aprendizagens com privilégios em determinados aspectos e esquiva-se de outros, cabe às instituições escolares possibilitar uma educação reflexiva aos educandos, para que os mesmos sejam 
capazes de exercer um olhar críticos em relação às culturas e suas práticas, com os diferentes mundos e conhecimentos.

De acordo com Hargreaves, Earl e Ryan (2001) já não é suficiente para as escolas proporcionar aos estudantes as capacidades básicas. Os alunos e alunas precisarão atingir capacidades mais complexas, pensamento crítico, soluções novas para problemas, trabalho independente e coletivo, distinção de ação em situações ambíguas, entre outras capacidades eminentes para conviver na sociedade contemporânea.

As mentes formadas pelas disciplinas perdem suas aptidões naturais para contextualizar os saberes, do mesmo modo que para integrá-las em seus conjuntos naturais. O enfraquecimento da percepção global conduz ao enfraquecimento da responsabilidade (cada qual tende a ser responsável apenas por sua tarefa especializada), assim como o enfraquecimento da solidariedade (cada qual não mais sente os vínculos com seus concidadãos) (MORIN, 2006, p. 41). Entretanto, a educação deve mostrar que não há conhecimento que não esteja, em algum grau, ameaçado pelo erro e pela ilusão.

Nesse cenário, parece cabível salientar que a escola tem como desafio captar novos métodos de ensino e ambientes de aprendizagem que sejam construídos sobre o que atualmente conhecemos a respeito do aprendizado e do desenvolvimento humano para preparar nossos estudantes para lidar com as exigências crescentes que a sociedade lhes reserva.

Hernández (2006), afirma que a função essencial da escola é favorecer a equidade, possibilitando que todos encontrem seu lugar para aprender, e a perspectiva de uma educação integrada contribui para esse movimento. A primeira finalidade de uma visão integrada da educação é a que oportuniza a criação de experiências de aprendizagem com sentido e, ao tê-la, os estudantes, os professores e os membros da comunidade se envolvem apaixonadamente no processo de aprender.

Faz-se necessário dar espaço a uma escola baseada em outra narrativa, em outra lógica que não responda a uma expectativa do dia de amanhã, ou se adaptar de maneira subordinada à triunfante economia de mercado. Narrativa essa que abrange a visão de diferentes integrações: da experiência, social, dos conhecimentos e do projeto curricular. Considerar, sobretudo, os interesses dos educandos e seu envolvimento ativo com as demandas escolares.

O currículo precisa ser elaborado pelas pessoas que estão envolvidas no processo de ensino e de aprendizagem. O currículo escolar na contemporaneidade precisa envolver o cultivo de capacidades que preconizem: o desenvolvimento da aprendizagem cognitiva profunda; o incentivo para a criatividade e para a inventividade entre os estudantes; utilização da pesquisa e do trabalho em redes e equipes. Para Hargreaves (2003), é fundamental desenvolver a capacidade de lidar com a mudança como possibilidade de melhorias para a educação e sociedade, por meio de processos cooperativos e colaborativos.

Acreditamos que as ações para uma escola mais inovadora dependem de mudanças que envolvem maior colaboração de todas as pessoas que fazem parte dela. Objetivos claros e compartilhados podem favorecer a confiança na relação entre as pessoas, ampliar o diálogo e reavaliar constantemente o processo de ensino e de aprendizagem. Tal processo perpassa a constituição do ser apenas racional, constitui-se na valorização dos aspectos afetivos, emocionais, físicos e sociais, considerando a intervenção do ser aprendente em diferentes tempos e espaços.

\section{AS METODOLOGIAS CRIATIVAS NO PROCESSO DE ENSINO E DE APRENDIZAGEM CONTEMPORÂNEO}

O que significa ensinar e aprender na contemporaneidade? Como ensinar para que o outro possa aprender? $\mathrm{O}$ que posso aprender enquanto ensino? $\mathrm{O}$ que podemos ensinar e aprender em 
colaboração? É possível um processo mais criativo? Certamente perguntas como essas instigam os pensamentos de muitos educadores e investigadores. Os processos de ensinar e aprender, sem dúvida, são distintos e muito peculiares, no entanto, tem relação direta no cotidiano escolar contemporâneo, o qual exige uma prática mediadora, reflexiva e dialógica.

Pérez Gómez (2015), afirma que o ensino e a aprendizagem relevantes exigem a atividade do sujeito em um processo contínuo de construção e reconstrução. A aprendizagem deve ser vista como um processo ativo de indagação, investigação e intervenção. Sustenta-se que o objetivo essencial da educação é aprender - aprender a criar, a resolver problemas, a pensar criticamente, a desaprender e reaprender, a agir colaborativamente e preocupar-se com os demais e o entorno - o processo de ensino e aprendizagem demanda inovação, o qual exige criatividade, imaginação, autonomia, ousadia e tolerância ao erro.

Por isso, a educação do século XXI deve promover uma mudança radical na ciência, ajudando as pessoas a se desenvolverem como seres completos e mais criativos. Para Bellón (2013), é preciso colocar em primeiro lugar a capacidade de exploração, organizar informações e tecer múltiplas relações entre diversas temáticas. É preciso abrir o espaço da sala de aula para a criatividade, ampliar visões e estimular a participação ativa de múltiplos autores sociais. $\mathrm{O}$ ser criativo signifca estar crescendo continuamente como pessoa e viver em uma dimensão em que o intimo, o universal, o todo e o particular se fundem numa consciência integral.

Aprender já não é sinônimo de apropriação passiva, de verdades imutáveis da escola tradicional, mas uma atividade poética, produtiva, criativa e transformadora, na qual estão inseridos tanto os professores e instituições educativas, quanto a família, as empresas, as autoridades e a sociedade em geral. Todos eles estão na interação com o meio ambiente em permanente transformação. (BÉLLON, 2012, p. 44)

É necessário uma escola criativa e transformadora. Hoje temos a oportunidade de converter a escola em um gigantesco laboratório de novas possibilidades cognitivas, onde se reúnem os processos convergentes e divergentes. É preciso criar novos conhecimentos para um mundo que reconhece que o novo é emergente. Por esses e outros motivos, acreditamos na relevância de estudar as metodologias criativas através do Design Thinking.

O Design Thinking é um conjunto de processos para abordar problemas, relacionados à aquisição de informações, análise de conhecimento e propostas de soluções. Como uma abordagem, é considerada a capacidade para combinar empatia em um contexto de um problema, de forma a colocar as pessoas no centro do desenvolvimento de um projeto, criatividade para geração de estrategiass e razão para analisar e adaptar as soluções para o contexto real. Para Brown (2010), o $D T^{1}$ ocorre em grupo, é centrado nas pessoas e busca liberar a criatividade, através de redes interdependentes de pequenas equipes. Nessa metodologia, os espaços são importantes, tendo em vista que a flexibilidade é elemento-chave de seu sucesso.

Além disso, tem pontos de partida e pontos de referência úteis ao longo do caminho, mas o continuum da inovação pode ser visto mais como um sistema de espaços que se sobrepõem do que como uma sequência de passos ordenados. O ponto fundamental do processo é que seja exploratória, com ações de idas e voltas, sem linearidade. A metodologia pode ser representada de forma visual por duas figuras ilustrativas que estão se tornando clássicas e muito práticas para quem utiliza a metodologia, pois sua representação visual facilita o entendimento e compreensão de quem a aplica na prática, seja de diferentes áreas acadêmicas ou profissionais.

${ }_{1}^{1}$ A partir de agora DT refere-se a Design Thinking 
Figura 1: Etapas da metodologia do Design Thinking

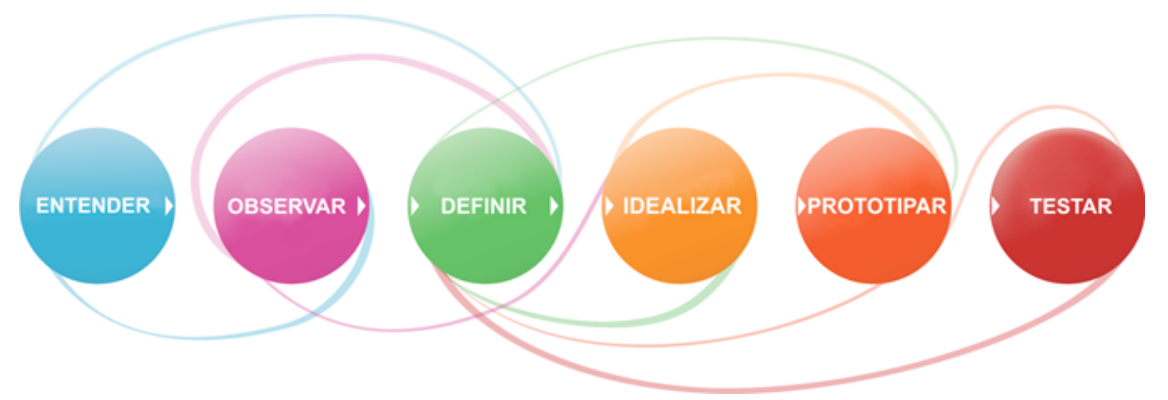

Fonte: D.school, Stanford. Disponível em $<$ http://dschool.stanford.edu $>$.

A figura acima caracteriza a metodologia como um processo de construção do pensamento, de uma forma orgânica e não linear, com a possibilidade de retornar as etapas iniciais mesmo quando o processo já estiver em fase final, na prototipagem ou teste (NITZSCHE, 2012).

A fase inicial é a da empatia que contempla as etapas de entendimento e observação, nas quais procuram-se vivenciar o ponto de vista e a realidade dos envolvidos no processo, inserindo o lado emocional dos mesmos já na fase inicial, sendo que ela estaria composta pelas fases de entendimento e observação. Aqui podem ser utilizadas diversas técnicas, como pesquisa de campo inicial (pesquisa exploratória) e técnicas emprestadas da antropologia, como entrevistas, trabalho de campo e outras.

A fase seguinte é denominada de definição do problema, na qual se pode analisar e perceber as questões trazidas da fase da empatia e questionar o problema ou desafio colocado de uma forma mais aprofundada e questionadora. Problema significa colocar em dúvida, questionar, dar caráter ou feição de problema. Não se trata somente de dar um problema a ser resolvido, mas de colocar as pessoas envolvidas em contato com a realidade para que possam observá-la, confrontá-la com a teoria e com as questões colocadas a partir do seu contexto e, a partir da etapa de empatia, revisitar o problema para, dessa forma, redefini-lo ou aprofundá-lo. Após o estudo do problema inicial podem surgir desdobramentos do mesmo, ou, novos problemas mais aprofundados e até mesmo mais alinhados às questões essenciais da realidade do indivíduo, sejam elas de ordem prática, emocional ou a outras situações.

Estabelecido o problema, parte-se para a etapa de ideação ou idealização. Os participantes do processo geram uma profusão de ideias, na qual importa a quantidade e não a qualidade das mesmas. Inicialmente, todas as ideias são consideradas válidas e viáveis, como forma de esgotar as possibilidades de soluções para o problema ou desafio. Nessa fase, o perfil de um público-alvo é definido, e as soluções criadas, a partir de ideias inovadoras, direcionam-se a esse público. Nessa fase, são realizadas sessões de brainstormings, gerando ideias que serão capturadas para a etapa seguinte.

A partir disso, segue-se para a etapa de convergência, na qual uma ou algumas ideias e soluções principais são selecionadas. Para auxiliar nessa etapa da convergência, podem ser utilizadas distintas ferramentas que auxiliam no processo de discussão e reflexão acerca das ideias geradas agrupando em temas que possuem alguma relação.

Partindo da seleção de ideias, surge a etapa de prototipagem ou prototipação e teste, quando a solução apontada é representada de uma maneira prática, seja através de dramatização, desenho, ou alguma outra forma criativa encontrada pelos participantes. Por prototipagem entendemos uma atividade de colocar uma ideia em prática, de construir a ideia ou solução e transformá-la em algo real, tangível, e passível de observação e avaliação por todos os participantes. 
O objetivo, nesta fase, é gerar uma vivência emocional conectada à solução, de forma que o indivíduo possa sentir e se perceber vivenciando a situação desejada. É o momento em que ideias abstratas ganham conteúdo formal e material, representando a realidade capturada e propiciando a validação de todo o conteúdo apreendido.

Como podemos perceber pela descrição do processo construtivo do $D T$, ele é realizado em etapas, no entanto, não pode ser pensado de forma linear, em uma sequência de fases estanques. Ao contrário, cada etapa permeia a outra, fazendo parte de um todo, que pode levar ao avanço de algumas etapas em determinado momento, ou um retorno às etapas iniciais, mesmo que a solução já esteja em sua fase final. Devido à sua natureza não linear, a configuração das fases de um processo pode se adaptar a um problema ou projeto em questão. Nesse sentido, é uma forma de pensar baseada em soluções ou focada em soluções, com um objetivo desafiador lançado no início, em vez de ser lançada já com um determinado problema.

Trazer os princípios do DT para a educação significou, buscar subsídios inovadores para o ambiente educacional, que favoreça prioritariamente o desenvolvimento integral do ser humano, através da criatividade, autonomia, autoria e protagonismo. É pensar na educação do futuro, com vistas nas necessidades vigentes. "A educação do futuro deverá ser o ensino primeiro e universal, centrado na condição humana. Estes devem reconhecer-se em sua humanidade comum e ao mesmo tempo reconhecer a diversidade cultural inerente a tudo que é humano.” (MORIN, 2006, p. 47).

De certa forma, o DT é um conjunto de ferramentas, métodos e processos pelos quais desenvolvemos novas respostas para os desafios, sejam eles grandes e ou pequenos. Através da aplicação do $D T$, é possível definir os problemas, entender as necessidades e limitações, debater soluções inovadoras, e buscar e incorporar o feedback sobre as ideias a fim de torná-los melhor e fortalecer a capacidade de gerar ideias criativas com vistas nas mudanças.

A relação do $D T$ com o processo de ensino e aprendizagem nos ambientes escolares se dá principalmente pelo engajamento colaborativo, criativo e a ruptura de poderes hegemônicos estabelecidos nos ambientes escolares. Além disso, como afirma Moraes:

A educação precisa estar em consonância com essa nova visão do mundo, com a sociedade almejada no futuro, e, para tanto, é necessário criar ambientes educacionais que extrapolem as questões pedagógicas, que busquem o entendimento da condição humana [...] Isso requer novos métodos de ensino, novos currículos, e novas práticas educacionais absolutamente diferentes das que estamos acostumados encontrar em nossas escolas. (MORAES, 1997, p. 112)

Por acreditar na mudança e nas pessoas, aceitar o erro e as incertezas é que tentamos buscar novas maneiras de pensar as práticas educativas e a relação do ensino e aprendizagem no ambiente escolar através da metodologia criativa DT. Diante disso, trazemos nesse estudo os relatos das pessoas que participaram dessa metodologia.

\section{RESULTADOS DE UMA EXPERIÊNCIA CRIATIVA E COLABORATIVA}

A experiência, relatada nesse artigo, proporcionou momentos de grande aprendizagem profissional e pessoal. Desenvolver oficinas de metodologias criativas, baseadas no $D T$, no contexto educacional foi sem dúvida desafiadora, tendo em vista que esta foi uma das primeiras experiências em que participaram conjuntamente a equipe diretiva, professores, estudantes e pais de uma escola de Educação Básica, Ensino Fundamental e Médio.

Foram realizados seis encontros, com duração de aproximadamente duas horas cada. No decorrer dos encontros, o grupo aproximou-se das diferentes etapas do DT, com o objetivo de repensar a escola. Como resultado do processo obteve-se reflexões profundas sobre o fazer da 
instituição e geração de muitas ideias e possibilidades para qualificar a escola com colaboração efetiva e criatividade entre todos os participantes.

Inicialmente, apresentamos para o grupo os objetivos da proposta e a conceituação teórica do DT. Para o desenvolvimento de cada uma das etapas, procuramos organizar os grupos de duas maneiras. Em um primeiro momento (etapas da observação e da empatia), os grupos identificaramse em função da persona que deveriam construir, estudantes juntos, docentes com docentes e assim por diante. Nas últimas oficinas, os grupos organizaram-se de forma mais heterogênea, onde cada grupo poderia ter um representante de cada persona, um docente, um estudante, um familiar e alguém da equipe diretiva. Em cada uma das oficinas houve um planejamento prévio, de acordo com tabela 1:

\section{Tabela 1: Esquema das oficinas}

Tema

\begin{tabular}{|c|c|c|}
\hline Oficina 1 & Apresentação inicial & $\begin{array}{c}\text { - Integração e apresentação } \\
\text { do grupo. } \\
\text { - Apresentação: O que é o } \\
\text { Design Thinking. } \\
\text { - Vivência em duplas. } \\
\text { (Quem sou? Qual meu } \\
\text { problema hoje?) }\end{array}$ \\
\hline Oficina 2 & Entender e Observar & $\begin{array}{l}\text { - Mapa da empatia } \\
\text { - Apresentação do mapa pelos } \\
\text { grupos. }\end{array}$ \\
\hline Oficina 3 & Definir & $\begin{array}{c}\text { Definição do problema: } \\
\text { diante da realidade da escola e } \\
\text { da observação das pessoas, } \\
\text { qual é o problema? }\end{array}$ \\
\hline Oficina 4 & Ideação & $\begin{array}{l}\text { - Brainstorming } \\
\text { - Escrever todas as ideias para } \\
\text { resolver o problema. } \\
\text { - Delimitar uma ou duas } \\
\text { ideias. }\end{array}$ \\
\hline Oficina 5 & Prototipagem & $\begin{array}{l}\text { - Deixar a ideia visível. } \\
\text { - Elaborar e montar um } \\
\text { protótipo da ideia. }\end{array}$ \\
\hline Oficina 6 & Testagem & $\begin{array}{c}\text {-Planejamento para } \\
\text { continuação das oficinas a fim } \\
\text { de colocar em prática os } \\
\text { projetos. } \\
\text {-Avaliação dos encontros. } \\
\text { - Relatos pessoais. } \\
\text { - Confraternização. }\end{array}$ \\
\hline
\end{tabular}

Fonte: As autoras.

No decorrer de cada um dos encontros foi notória a aproximação e maior colaboração entre os participantes. Apesar das distintas necessidades expressas por cada uma das pessoas, houve como objetivo em comum, melhorar a qualidade do ensino e a aprendizagem dos estudantes por práticas mais interdisciplinares e com mais diálogo entre todos os envolvidos (equipe diretiva, educadores, educandos, pais e funcionários em geral). Como resultado dos protótipos, registrouse a construção de maquetes de uma escola interligada ao mundo externo por distintas pontes e por ligações diretas entre uma sala de aula e outra, unindo as distintas disciplinas e áreas do conhecimento. 
Nesse sentido, a partir dessas vivências foi possível coletar os relatos dos participantes e estabelecer diálogo com diferentes autores, os quais subsidiaram nossa compreensão sobre tais relatos e os efeitos e sensações das oficinas para cada participante.

O que disseram os docentes:

Os docentes ressaltaram como um dos aspectos mais relevantes das vivências das oficinas, o trabalho em equipe e a diversidade:

Podemos trabalhar em grupos com pessoas de áreas diversas e opiniões divergentes. A partir delas, construir uma convergência criativa que pode beneficiar a todos. Gosto muito do trabalho em equipe. Eu penso que podemos divergir muito e a partir dessa divergência criar uma solução que e a gente coloca muitas outras habilidades, situações que no nosso componente curricular sozinha não seria possível desenvolver aquela habilidade. Sinto-me bem. Aprender com aquilo que não é da minha área, mas que contribui para diferentes situações. Trabalhar assim me encanta. (Professora 1)

Para Pérez Gómez (2015), a aprendizagem se enriquece em contextos onde há relações de apoio, em que as pessoas podem aprender de e com os outros. Os cenários de colaboração, cooperação e de apoio mútuo favorecem a aprendizagem e estimula a troca de informações. Outro aspecto a ser destacado é que o trabalho em equipe estimula a imersão em território incerto da busca, da investigação e da inovação, o que parece ser muito coerente para as práticas escolares na contemporaneidade. A aprendizagem em grupos desenvolve a habilidade de compartilhar as expectativas, ouvir as outras pessoas, lidar com pontos de vistas distintos e contraditórios e buscar conexões, aproveitando os talentos de diferentes olhares de cada pessoa.

A fala da Professora 2 retrata os dizeres citados e reafirma a relevância da aprendizagem coletiva com a valorização indispensável do desenvolvimento individual:

O interessante desse trabalho é isso, vai te descobrindo. Possibilidade de aplicar essa metodologia na sala de aula é viável. A análise do erro traz possibilidades novas. Se abrir para os medos. Juntos construir, criar junto com os alunos. A gente como professor tem que ter olhar coletivo e individual e abrir-se para as situação de incertezas. (Professora 2)

A nossa compreensão do mundo é formada também pelo conhecimento das outras pessoas, afirma Robinson (2012). Estamos entrelaçados em redes de conhecimento, por isso, a criatividade depende das relações e é movida mais pela colaboração do que para esforços individuais. Torna-se vital pensar e agir de maneira diferente, sem temer o erro e aprender a com a incerteza e com a complexidade.

O que a equipe diretiva pensa:

No decorrer das experiências vivencias pela proposta das oficinas, ficou visível o encantamento da equipe diretiva com a metodologia do DT, a seguir alguns depoimentos:

Não temos outra saída na escola senão dinamizar esse tipo de processo e levar adiante. Essa metodologia tem um referencial teórico sólido e parece ter eficácia para a educação. Quebrar o modelo mental que o domínio está com o professor, domínio centralizador. Dar autonomia de quem está no processo. Criar o sentimento que pode dar errado. Quebrar paradigmas. (Gestor)

Ultrapassando os muros do colégio. Minha expectativa é muito grande. O que queremos é que os estudantes tenham aprendizagens significativas. (Pedagoga) 
Gostaria que pudéssemos dar continuidade a essa metodologia, e também que não perdesse de vista esse grupo. Que esse grupo fosse protagonista da escola. Colocar a metodologia em ação. (Diretora)

Cremos que esses relatos por si só justificam a importância de repensar a escola coletivamente e democraticamente, em um lugar em que todos aprendem uns com os outros. Uma vez que a escola permite abrir-se para reflexões e planejamento coletivo, busca seu próprio caminho com o intuito de alcançar os objetivos para que processos de ensino e aprendizagem aconteçam com significado para a vida de cada pessoa envolvida. Como afirma Robinson (2012), transformar a educação de uma forma geral sempre requer a transformação das escolas individualmente. $\mathrm{O}$ desafio está em propagar os princípios da criatividade para a educação, de modo que cada escola desenvolva abordagens próprias diante dos desafios que enfrentam. Não existem receita que possam ser passadas, o que sim é possível é realizar um trabalho colaborativo entre todos os participantes de cada comunidade escolar, possibilitando o diálogo e a busca conjunta de possíveis soluções para os diferentes contextos.

O que disseram os pais e os estudantes:

O principal ponto abordado na fala de uma das mães é a mudança de concepção do funcionamento da escola e a compreensão de que quando os problemas são resolvidos em conjunto e com novos olhares, todos temos a ganhar.

O maior ganho é justamente mostrar para os alunos que há muitas possibilidades. Possibilidade de interação. Achei as oficinas pela formação do grupo diverso, com todas as visões. Com possibilidade de fazer trocas com todos os envolvidos, outros olhares, mas com um objetivo comum que é o melhor para a aprendizagem. Ter problema não é problema. (Mãe)

Sobre isso, Guerra (2009) propõe que a aprendizagem na escola será eficaz quando o interesse emergir da própria escola. Para aprender tem que querer e ter olhos abertos para poder enxergar, a mente aberta para analisar, o coração disposto para assimilar e os braços dispostos para colocar em prática. "Todos falam na escola. O que falta é saber escutar e saber analisar o que se escutou”. (p.170).

A oportunidade de se manifestar, ser escutado e valorizado pelos educadores, pais e gestores como resultado dos encontros, foi relatado com satisfação pelos alunos. Os estudantes tem muita necessidade de expor as suas ideias e considera-las é fundamental para um desenvolvimento de qualidade.

Essas oficinas proporcionaram a ideia da confiança, aceitar a opinião do outro. Ouvir efetivamente, independentemente da idade. Criei confiança nesse grupo a partir do momento que percebi que minhas ideias foram consideradas e levadas a sério. (Aluno 1)

Outro fator, que merece ser destacado, é a participação dos estudantes no planejamento escolar, como podemos perceber na fala de outro aluno:

Mudei a mentalidade, consegui compreender melhor as situações cotidianas da escola. Muitas vezes nós alunos não entendemos porque temos que passar por determinadas situações, como reformas por exemplo, mas quando estamos participando do processo de planejamento da escola, podemos entender que existe planejamento que envolva tudo que existe, e todas as pessoas estão envolvidas. (Aluno 2) 
Nesse sentido, Hargreaves (2003), diz que uma condição previa para elaborar novas e eficazes formas de trabalhar em aula, é que os alunos e professores discutam implicações de qualquer enfoque inovador do seu trabalho em comum. Devem aventurar-se juntos na novidade e na resolução de problemas que envolve o contexto escolar. Trata-se de visualizar a escola como um ambiente desafiador, de experiências formativas e do desenvolvimento de cidadãos críticos e participativos.

Para Santos (2010) seguindo a perspectiva sócio-histórica, "é pela aprendizagem com os outros que o indivíduo constrói constantemente o conhecimento, promovendo o desenvolvimento mental e passando, desse modo, de um ser biológico a um ser humano" (P 137-138). A educação é fundamental para o desenvolvimento do ser humano, pois acredita-se que pode ser a livre realização de nossas potencialidades evolutivas e criativas, e que pode ser crítica para nossa sobrevivência coletiva.

Outo depoimento que foi trazido por um estudante, refere-se à necessidade de a escola e família proporcionar um ambiente de confiança. Essa palavra apareceu de forma destacada na prototipagem dos estudantes, quando no centro do desenho de uma árvore foi colocada a palavra. Esse diálogo fez com que pais e educadores ouvissem o depoimento dos estudantes e posteriormente refletissem no grupo sobre essa demanda.

Por fim, como um dos resultados mais significativos, foi a demonstração de interesse dos participantes em dar continuidade a essa metodologia com toda a escola, através da implementação do projeto e das oficinas de $D T$ com outros professores, estudantes e familiares. A proposta das oficinas pode viabilizar aprendizagens mais significativas e disruptivas em relação aos processos tradicionais e propor assim, mudanças interdisciplinares, as quais têm características mobilizadoras para as ações de ensinar e aprender em diferentes direções, espaços e tempos.

\section{CONSIDERAÇÕES FINAIS}

A educação no ambiente escolar não comporta mais processos lineares. Aprender e conhecer o mundo contemporâneo "nos obriga" a reconhecer que o conhecimento é potencializado em espaços novos. As escolas precisam ampliar suas fronteiras e, para isso, requerem novos métodos. Os docentes, nesse âmbito, encontram-se com um novo ofício mediante a velocidade das mudanças tecnológicas e a quantidade de informações: estar em contínua formação e proporcionar oportunidades de aprendizagem para atender as demandas sociais atuais.

Acreditamos que a possível aplicação da metodologia DT nos processos de ensino e aprendizagem na escola possa proporcionar uma metodologia que respeite novos tempos e diferentes espaços, com maior engajamento, participação e colaboração entre as pessoas, além de permitir questionamentos e novas ações sobre os fazeres da escola, pelos próprios sujeitos que dela fazem parte. Os resultados dessa pesquisa apontaram para a satisfação dos participantes, tendo em vista envolvimento efetivo dos mesmos na criação de possibilidades para melhorar o ambiente escolar e nos vínculos que foram estabelecidos e estreitados entre estudantes, docentes, gestão e pais, mediante a proposta.

Em síntese, entendemos que "a pretensão" de construir uma nova perspectiva para a escola está relacionada com a prática curricular relacionada com problemas reais, ou seja, adotar uma visão ampla e aceitar os interesses dos educandos, sem as limitações que são impostas pelas disciplinas. Nesse sentido, necessitamos optar por estratégias criativas que perpassam a repetição e os exercícios clássicos. Portanto, percebendo a possibilidade de ações distintas, o desafio do processo de ensino e aprendizagem depende de todos os envolvidos, e requer um diálogo amplo, aberto e constante para que esse processo realmente aconteça. Requer uma visão mais integral das pessoas, 
a qual valoriza aspectos cognitivos, emocionais, sociais e culturais. O real sentido das mudanças nas metodologias da educação escolar está na conjuntura entre os conceitos e atitude das pessoas, pelo significado e direcionamento desenvolvido de acordo com o interesse e necessidades de cada realidade.

A partir dos pressupostos detectados no decorrer das oficinas, nos questionamos a respeito de quais seriam as mudanças para o processo de ensino e de aprendizagem quando utilizadas as metodologias criativas? Sustentados pelo engajamento entre as teorias e as práticas em estudos, alguns achados emergiram, os quais consideramos relevantes para servir de conexão e base para próximas pesquisas. Nesse sentido, concluímos que as mudanças que emergem de um processo proposto pelas metodologias criativas são:

- Partir da premissa que existe visões diferentes acerca de uma realidade.

- Empatia, compreender e se colocar no lugar do outro.

- Diálogos, trocas de experiências e colaboração.

- Valorização dos conhecimentos prévios de cada pessoa e levar em consideração as ideias e opiniões, sejam elas individuais ou coletivas.

- Resolução de problemas, busca pela solução de problemas coletivamente.

- Aprendizagem pela pesquisa.

- O erro com parte do processo de ensino e de aprendizagem.

- Transformar ideias em protótipos (tornar a ideia tangível e passível de receber feedback dos outros) e colocá-las em práticas concretas.

Por fim, consideramos que um dos aspectos fundamentais no processo de ensinar e aprender é ter como ponto de partida questões sobre os problemas relacionados com situações da vida real. O sentido e a compreensão de situações da vida real são estratégias de aprendizagem que permitem o desenvolvimento integral do ser humano, mediante estímulos para as capacidades de relacionar-se com os outros e com o mundo, entender a si e aos outros e agir de maneira colaborativa e criativa na sociedade a qual vivemos.

\section{REFERÊNCIAS}

BÉLLON, Francisco Menchén. A escola galáctica, a escola criativa transformadora: Uma Nova Consciência. In: TORRE, Saturnino de la; PUJOL, Maria Antônia; SILVA, Vera Lúcia de Souza (Coords.). Inovando na sala de aula - Instituições transformadoras. Blumenau: Nova Letra, 2013.

BROWN, Tim. Design Thinking: uma metodologia poderosa para decretar o fim das velhas ideias. Rio de Janeiro: Elsevier, 2010.

DAMASCENO, Ednacelí Abreu. A Reconfiguração do Currículo na Sala de Aula pela Cultura do Desempenho. In: SANTOS, Lucíola Licínio de C. P.; FAVACHO André Márcio P. (Org.). Políticas e Práticas Curriculares: desafios contemporâneos. 1ed.Curitiba: CRV, 2012, v. 01, p. 151 165.

GUERRA, Miguel Angel S. Escuelas para la democracia: culturas, organización y dirección de instituciones educativas. Madrid: Wolters Kluwer, 2009.

HARGREAVES, Andy; Shirley, Dennis. La cuarta vía: el prometedor futuro del cambio educativo. Barcelona, Espanha: Octaedro, 2012.

HARGREAVES, Andy. Replantear el cambio educativo: un enfoque renovador. Amorrortu, 2003. MARTÍN-BARBERO, Jesus. Desafios culturais da comunicação à educação. Comunicação \& Educação, 181, 51-61, 2000 
MORIN, Edgar. Os sete saberes necessários à educação do futuro. Brasília, Brasil: Unesco, 2006. MORAES, Maria Cândida. O paradigma educacional emergente. Campinas: Papirus, 1997.

MOSQUERA, Juan José Mouriño. Pós-modernidade, cultura e professorado: uma análise da subjetividade docente. Educação, 23 (41), p. 31-45, 2000.

NITZSCHE, Rique. Afinal, o que é o Design Thinking? São Paulo: Edições Rosari, 2012.

PÉREZ GÓMEZ, Angel I. Educação na era digital: a escola educativa. Porto Alegre: Penso, 2015. PÉREZ LINDO, Augusto. Para que educamos hoy? Buenos Aires: Biblios, 2010.

POZO, Juan Ignacio. Aprendizes e mestres: a nova cultura da aprendizagem. Porto Alegre: Artmed Editora, 2002.

SANCHO, Juana Maria. Em busca de respostas para as necessidades educacionais da sociedade atual. Uma perspectiva multidisciplinar da tecnologia. Revista Linhas, 14(27), 09-44, 2013.

SANTOS, Bettina Steren dos, Boza. Ángel Carreño. A motivação em diferentes cenários. Porto Alegre: EDIPUCRS, 2010.

VYGOTSKY, Lev Seminovich. El desarrollo de los procesos psicológicos superiores. Barcelona: Critica, 1979.

Submetido em outubro de 2020. Aprovado em marco de 2021.

\section{Informações do(a)(s) autor(a)(es)}

Bettina Steren dos Santos

Pontifícia Universidade Católica do Rio Grande do Sul - PUCRS

E-mail:bettina@pucrs.br

ORCID: https://orcid.org/0000-0002-5595-232X

Link Lattes: http://lattes.cnpq.br/3740903204981170

Carla Spagnolo

Colégio Marista Rosário

E-mail: carlaspagnolo1@gmail.com

ORCID: https://orcid.org/0000-0003-3798-2995

Link Lattes: http://lattes.cnpq.br/2774032150211830

Caroline Bücker

IDEALIZA

E-mail: carolinebucker@gmail.com

ORCID: https://orcid.org/0000-0002-6066-5579

Link Lattes:

https://wwws.cnpq.br/cvlattesweb/PKG_MENU.menu?f_cod=F64BC86C71E1815AE587EEA5626AB 969 